NASA

Technical Memorandum105653

\section{1,37}

AVSCOM

Technical Report 91-C-027

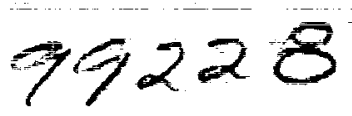

\title{
Optimum Design of a Gearbox for Low Vibration
}

$p .10$

Katsumi Inoue, Dennis P. Townsend, and John J. Coy

Lewis Research Center

Cleveland, Ohio

(NASA-TM-105653) OPTIMUM DESIGN TF A

GEARBOX FOR LOW VIBRATION (IVASA) $10 \mathrm{p}$
$N 92-28476$

Unclas

G 3/37

\section{Prepared for the}

Sixth International Power Transmission and Gearing Conference sponsored by the American Society of Mechanical Engineers Scottsdale, Arizona, September 13-16, 1992 


\title{
OPTIMUM DESIGN OF A GEARBOX FOR LOW VIBRATION
}

\author{
Katsumi Inoue ${ }^{\mathrm{I}}$ \\ Tohoku Lniversity \\ Sendai, Japan \\ and \\ Dennis P. Townsend and John J. Coy \\ National Aeronautics and Space Administration \\ Lewis Research Center \\ Cleveland, Ohio 44135
}

\section{ABSTRACT}

A computer program was developed for designing a low vibration gearbox. The code is based on a finite element shell analysis method, a modal analysis method, and a structural optimization method. In the finite element analysis, a triangular shell element with 18 degrees-of-freedom is used. In the optimization method, the overall vibration energy of the gearbox is used as the objective function and is minimized at the exciting frequency by varying the finite element thickness. Modal analysis is used to derive the sensitivity of the vibration energy with respect to the design variable. The sensitivity is representative of both eigenvalues and eigenvectors. The optimum value is computed by the gradient projection method and a unidimensional search procedure under the constraint condition of constant weight.

The computer code is applied to a design problem derived from an experimental gearbox in use at the NASA Lewis Research Center. The top plate and two side plates of the gearbox are redesigned and the contribution of each surface to the total vibration is determined. Results show that optimization of the top plate alone is effective in reducing total gearbox vibration.

\section{INTRODUCTION}

The vibration of a power transmission gear system is initiated by the gear mesh. The vibration energy is transmitted to the gearbox housing through the shafts and bearings, and the gearbox housing radiates the structure-borne noise. The vibration and generated noise are influenced by manufacturing precision, alignment errors of the gears, and the design of the gearbox. These factors affect the total quality of the system and are becoming more important.

In order to estimate the vibration of a gear system, it is necessary to understand the excitation characteristics and to evaluate the dynamic behavior of the system. With respect to excitation characteristics, Kubo, Kiyono, and Fujino (1986) proposed the concept of the total vibration exciting force that integrates the effects of

\footnotetext{
${ }^{1}$ National Research Council - NASA Research Associate.
}

manufacturing and alignment errors and periodical change of tooth mesh stiffness. However, the evaluation of the system's dynamic behavior is related to the modeling of the system. Some approaches presented recently include the analysis of multistage gear systems coupled with gearbox vibrations (Choy et al., 1991) and the analysis of vibration transmission in a single-stage gearbox by the building block approach (Takatsu et al., 1991). These are not simple simulations. However, once the vibration of a gearbox is analyzed, the sound radiation from the gearbox can be estimated by using the results as input data to BEMAP (boundary element method for acoustic prediction) (Seybert and $W \mathrm{u}, 1989$ ) or a similar boundaryelement-based, acoustic-intensity analysis. Consequently, the vibration and noise of a gearbox can be estimated to some extent.

Generally, the vibration of the gear system is sensitive to the dynamic characteristics of the gearbox. The reduction of noise levels is linked to reduction of the gearbox vibration levels. In contrast to progress made in the dynamic analysis of gear systems mentioned previously, the systematic procedure for reducing gearbox vibration levels is not adequate. The technique to avoid a resonance by shifting the natural frequency is often used to reduce vibration. A mass or stiffener is added at an efficient position on the gearbox. Although this can be an effective method, it is not easy to determine the best position on the gearbox or to estimate a suitable natural frequency shift. From this viewpoint, the authors have proposed a method to design plates (Inoue, Kato, and Ohnuku, 1990) and thinplate structures (Inoue, Townsend, and Coy, 1992). The overall vibration energy is adopted as the parameter for estimating the quality of a design and is minimized at a given frequency by varying the finite element thickness. The optimization problem is solved under the constraint of constant weight. In this paper the method is applied to the design of a gearbox made from steel plates, and the vibration reduction is demonstrated analytically. The exciting forces applied at the bearing locations are assumed to be known, although influenced by the gearbox's dynamic characteristics determined in the design process. The purpose of this research was to design a low-vibration gearbox. 


\section{OPTLMUM DESIGN PROCEDURE}

\section{Minimization of Overall Vibration Energy}

The theoretical basis of the proposed method is given by Inoue, Townsend, and Coy (1992) and is summarized here. The equation of motion of a structure is given in the matrix form as follows:

$$
[\mathrm{M}]\{\overrightarrow{\mathrm{u}}(\mathrm{t})\}+[\mathrm{C}]\{\dot{\mathrm{u}}(\mathrm{t})\}+[\mathrm{K}]\{\mathrm{u}(\mathrm{t})\}=\{\mathrm{f}(\mathrm{t})\}
$$

where $[M]$ is the mass matrix, $[C]$ is the damping matrix, $[K]$ is the stiffness matrix, $\{\mathrm{u}(\mathrm{t})\}$ is the time-varying displacement vector, and $\{\mathrm{f}(\mathrm{t})\}$ is the time-varying exciting force vector. Proportional damping is assumed, and the damping matrix is obtained by the linear combination of the mass matrix and the stiffness matrix:

$$
[\mathrm{C}]=\alpha[\mathrm{M}]+\beta \mid \mathrm{K}]
$$

where $\alpha$ and $\beta$ are the coefficients to define the proportional damping matrix. The modal matrix $[\Phi]$ is defined by the assembly of normalized eigenvectors $\left\{\phi_{r}\right\}$ :

$$
\left.[\Phi]=\left\{\phi_{1}\right\},\left\{\phi_{2}\right\}, \ldots,\left\{\phi_{n}\right\}\right]
$$

where $\mathrm{n}$ indicates the number of eigenvectors considered. When the structure is excited by a harmonic force of angular frequency $\omega$, the force vector and vibration displacement vector are given by

$$
\begin{gathered}
\{f(t)\}=\{F\rangle e^{j \omega t} \\
\left.\{u(t)\}=\{U\} e^{j \omega t}=\mid \Phi\right]\{\xi\} e^{j \omega t}
\end{gathered}
$$

where $\{F\}$ is amplitude of exciting force, $\{\mathrm{U}\}$ is amplitude of displacement, $\{\xi\}$ is the vector defined as $\{U\}=\{\Phi\}\{\xi\}$, and $j$ is the inaginary unit. Substituting Eq. (4) in Eq. (1), and premultiplying it by $[\Phi]^{\mathrm{T}}$, the $\mathrm{n}$ independent algebraic equations are obtained to evaluate the vector $\{\xi\}$. The rth component is given in the following form by solving the equation

$$
\xi_{\mathrm{r}}=\left\{\phi_{\mathrm{r}}\right\}^{\mathrm{T}}\{\mathrm{F}\} /\left(\left(\lambda_{\mathrm{r}}-\omega^{2}\right)+\mathrm{j} \omega\left(\alpha+\beta \lambda_{\mathrm{r}}\right)\right)(\mathrm{r}=1,2, \ldots, \mathrm{n})
$$

In the expression, $\lambda_{r}$ denotes the rth eigenvalue. Therefore, the amplitude $\{U\}$ for the vibration displacement is obtained by substituting $\{\xi\}$ into $\mathrm{Eq}$. (4).

The vibration velocity $\{\dot{u}(t)\}$ is given by the similar form as shown in Eq. (4).

$$
\{\dot{u}(t)\}=\{\dot{U}\} e^{j \omega t}=[\Phi]\{\dot{\xi}\} e^{j \omega t}
$$

The velocity can also be derived directly by differentiating the displacement in Eq. (4); therefore, the following equation is obtained by equating the differentiation to Eq. (6):

$$
\{\dot{\xi}\}=j \omega\{\xi\}
$$

Therefore, the real and imaginary parts of the rth component $\dot{\xi}_{\mathrm{r}}$ are obtained as follows:

$$
\begin{aligned}
& \dot{\xi}_{\mathrm{rR}}=\left(\alpha+\beta \lambda_{\mathrm{r}}\right)\left\{\phi_{\mathrm{r}}\right\}^{\mathrm{T}}(\mathrm{F}\} /\left\{\frac{1}{\omega^{2}}\left(\lambda_{\mathrm{r}}-\omega^{2}\right)^{2}+\left(\alpha+\beta \lambda_{\mathrm{r}}\right)^{2}\right\} \\
& \dot{\xi}_{\mathrm{rI}}=\frac{1}{\omega}\left(\lambda_{\mathrm{r}}-\omega^{2}\right)\left\{\phi_{\mathrm{r}}\right\}^{\mathrm{T}}\{\mathrm{F}\} /\left\{\frac{1}{\omega^{2}}\left(\lambda_{\mathrm{r}}-\omega^{2}\right)^{2}+\left(\alpha+\beta \lambda_{\mathrm{r}}\right)^{2}\right\}
\end{aligned}
$$

where $\mathrm{R}$ and $\mathrm{I}$ are the real and imaginary parts and $\{\ldots\}^{\mathrm{T}}$ denotes transpose matrix. The vibration energy $T$ of the structure is given by

$$
\begin{aligned}
\mathrm{T} & =\frac{1}{2}\left\{\dot{U}^{*}\right\}^{\mathrm{T}}[\mathrm{M}]\{\dot{\mathrm{U}}\} \\
& =\frac{1}{2}\left\{\dot{\xi}^{*}\right\}^{\mathrm{T}}[\Phi]^{\mathrm{T}}[\mathbf{M}][\Phi]\{\dot{\xi}\} \\
& =\frac{1}{2}\left\{\dot{\xi}^{*}\right\}^{\mathrm{T}}\{\dot{\xi}\}
\end{aligned}
$$

where $\left\{\dot{U}^{*}\right\}$ and $\left\{\dot{\xi}^{*}\right\}$ show the conjugate complex of $\{\dot{U}\}$ and $\{\dot{\xi}\}$. The energy is, therefore, represented by the following expression:

$$
T=\frac{1}{2} \sum_{r=1}^{n}\left(\dot{\xi}_{\mathrm{rR}}^{2}+\dot{\xi}_{\mathrm{rI}}^{2}\right)
$$

The sensitivity of the vibration energy with respect to the design $\ldots . .$. variable $x_{i}(i=1, \ldots, m)$ is given by

$$
\frac{\partial T}{\partial x_{i}}=\sum_{r=1}^{n}\left(\dot{\xi}_{r R} \frac{\partial \dot{\xi}_{r R}}{\partial x_{j}}+\dot{\xi}_{r I} \frac{\partial \dot{\xi}_{r I}}{\partial x_{i}}\right)
$$

Since $\alpha, \beta, \omega$, and $\{F\}$ in $\mathrm{Eq} .(8)$ are independent of the design variable, the sensitivity of the vibration energy is represented by a function of the sensitivities of the eigenvalue and the eigenvector. The evaluation of the sensitivities of both eigenvalue and eigenvector is based on the method proposed by $\bar{F}$ ox and Kapoor (1968).

The optimum solution is obtained by minimizing the vibration energy under the constraint of constant weight. The element thickness is adopted as the design variable and limited by specified minimum and maximum values. The gradient projection method (Rosen, 1961) was used for the optimization procedure in this research. The value of the energy at every iteration is saved and used to determine convergence. The convergence criteria is $1 / 1000$ relative variation.

\section{Optimum Design Program}

A computer program was developed based on the procedures previously described. The program consists of two main parts. The first part is the analyzer, which is composed of the finite element analysis, the eigenvalue analysis, and the evaluation of the vibration energy using modal analysis. The second part is the optimizer, which includes the sensitivity analysis and search procedure for the optimum value.

In the finite element analysis, the program is coded to make the design program as compact and flexible as possible. If the total 
degrees-of-freedom is constant, using a small number of highprecision elements generally leads to good results. However, the acceptable degree-of-freedom of the element should be within limits in this research because several elements are necessary to model the three-dimensional complex surface. Therefore, a triangular shell element with 18 degrees-of-freedom is used. The triangular shell element is formed by combining the elements for plate bending and plane problem analyses given by Zienkiewicz and Cheung (1967). The consistent mass matrix used for this analysis is evaluated using the numerical integration method. The accuracy of the finite element analysis is briefly discussed in the Appendix.

The program is configured on a Digital Equipment Corporation VAX cluster at NASA Lewis Research Center and executed interactively for small models. For large models the program is run on the Cray XMP/28 supercomputer. The program is written in FORTRAN 77 with no special software or hardware requirements.

\section{MODELING AND EIGENVALUE ANALYSIS OF GEARBOX}

Figure 1 shows the gearbox used as a design model. This gearbox is used in the NASA Lewis gear-noise test facility (Oswald et al., 1991) and is made of steel plates. The origin of a Cartesian coordinate frame is placed at the center of the bottom plate, and the positive $Z$ axis is defined upward and normal to the bottom plate. The $\mathrm{Y}$ axis is parallel to the direction of the shafts. The overall dimensions of the gearbox are approximately 324 by 248 by $270 \mathrm{~mm}$ (dimensions in $\mathrm{X}, \mathrm{Y}$, and $\mathrm{Z}$ directions). The four side plates are welded together and to the bottom plate. The top plate is bolted to the side plates. To simplify the formulation, the gearbox is modeled as a simple box by using 256 triangular shell elements with all surfaces continuously connected. The stiffeners and the four circular holes for the bearings are neglected in the model as is the supportive effect of the shafts. These simplifications may be reexamined and more elements used for a precise analysis, while still conserving the basic concept of the proposed method. The number of elements is fixed in this research only to limit computer time. The four corners of the bottom are fixed. Figure 2 shows the mesh pattern.

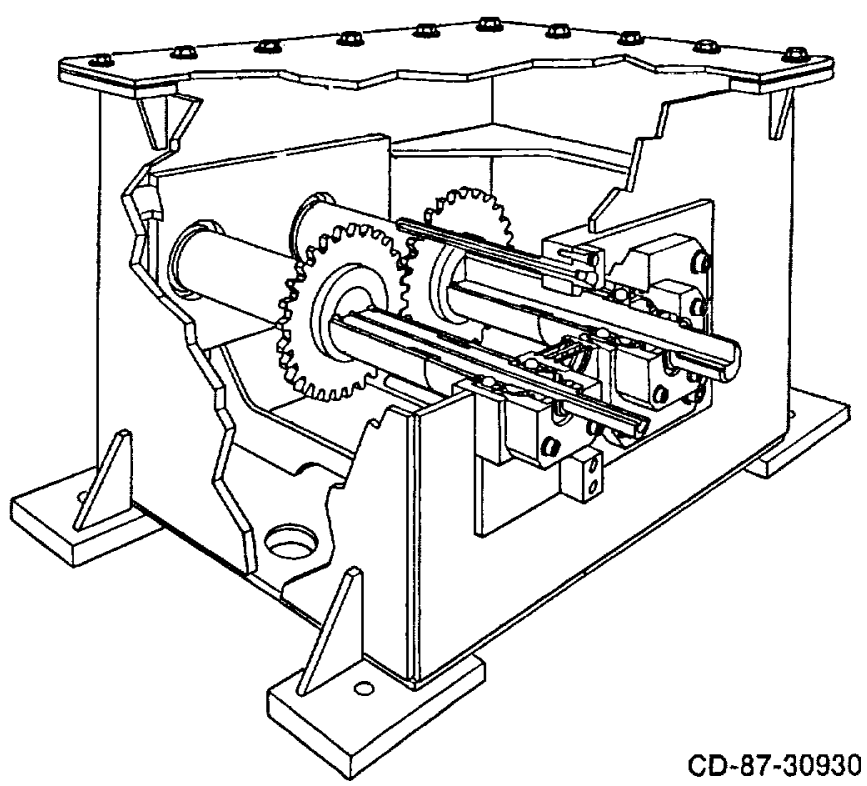

Figure 1.-Gearbox of NASA gear-noise rig.

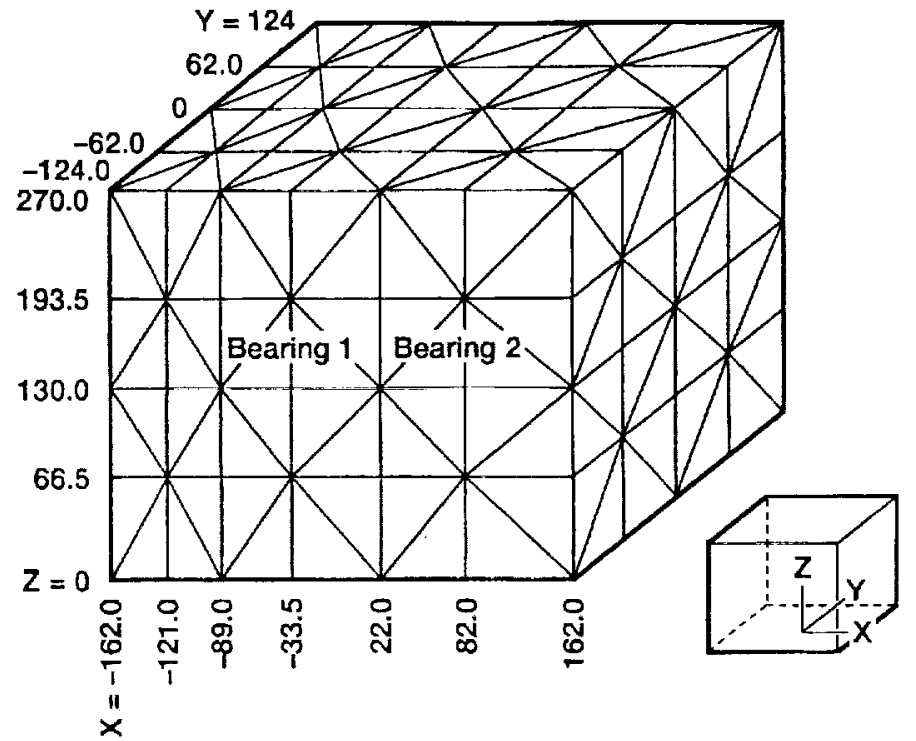

Figure 2.-Mesh pattern used for the optimum design of NASA gearbox.

The six surfaces are identified by the numbers 1 to 6 as follows: surface 1 , the top; surfaces 2 and 4 , the plates at $Y=124$ and -124 ; surfaces 3 and 5 , the plates at $X=162$ and -162 ; and surface 6 , the bottom. The thickness of the portions for the bearing housings at $-121 \leq X \leq 82$ and $66.5 \leq Z \leq 193.5$, is $22.4 \mathrm{~mm}$; the other elements are $6.3 \mathrm{~mm}$ thick. The constants used in this research are modulus of elasticity $=206 \mathrm{GPa}$, Poisson's ratio $=0.3$, mass density $=8000 \mathrm{~kg} / \mathrm{m}^{3}$, coefficients for composing proportional damping matrix $\alpha=1.0 \mathrm{sec}^{-1}$, and $\beta=5.0 \times 10^{-7} \mathrm{sec}$.

The eigenvalue problem is solved first to obtain the dynamic characteristic of the gearbox. The lower 10 natural frequencies and mode shapes are summarized in Table 1 . The mode shape of each surface is represented as, for example, $\left(m_{x}, m_{y}\right)$, which indicates that $m_{x}-1$ and $m_{y}-1$ nodal lines are observed in $X$ and $Y$ directions. The calculated fundamental natural frequency of $475 \mathrm{~Hz}$ is approximately 4.4 percent less than the result of measurement in the report by Lim, Singh, and Zakrajsek (1989). Some other measurement data are shown in this report, but there are no modes that coincide with the calculated results. This may be caused by neglecting the effects of stiffeners and shafts.

\section{VIBRATION OF GEARBOX RESULTING FROM UNIT HARMONIC FORCES}

Unit harmonic forces $I N$ are applied to the four positions of the bearings in the direction of the line of action, and the total vibration energy is calculated for the exciting frequency, which is given at every $10 \mathrm{~Hz}$ between 500 to $1500 \mathrm{~Hz}$. The energy is evaluated on the basis of the lower 30 modes. Since the natural frequency of the 30 th mode is $2448 \mathrm{~Hz}$, which is higher than the considered frequency range, 30 modes is enough for this calculation. The vibration energy is shown by the broken line in Fig. 5. Ten peaks are observed in the range at $540,580,610,770,940,1240,1280,1320,1400$, and $1460 \mathrm{~Hz}$, respectively. Since the energy is calculated at every $10 \mathrm{~Hz}$, the peaks do not coincide exactly with the natural frequencies, some of which are shown in Table 1 . However, they indicate the resonance approximately. 
TABLE 1.-LOWER 10 NATURAL FREQUENCIES AND MODE SHAPES OF GEARDOX

\begin{tabular}{|c|c|c|c|c|c|c|c|}
\hline \multirow{2}{*}{$\begin{array}{c}\text { Natural } \\
\text { frequency } \\
\text { number. } \\
i\end{array}$} & \multirow{2}{*}{$\begin{array}{c}\text { Fre- } \\
\text { Queacy } \\
\left(\mathbf{l}_{j}\right) \\
\text { II } \\
\end{array}$} & \multicolumn{6}{|c|}{ Surface sumber, mode shape } \\
\hline & & $1\left(\mathbb{m}_{x}, \mathbb{m}_{x}\right)$ & $2\left(m_{n}, m_{2}\right)$ & $3\left(\mathrm{~m}_{y}, \mathrm{~m}_{\mathrm{s}}\right)$ & $4\left(m_{x}, m_{n}\right)$ & $5\left(m_{y}, \omega_{1}\right)$ & $6\left[\mathrm{~m}_{x}, \mathrm{~m}_{y}\right]$ \\
\hline 1 & 475 & $-(1,1)$ & ${ }^{b}[1,1)$ & $\cdot(1,1)$ & $b_{(1,1)}$ & $4(1,1)$ & $\cdot(1,1)$ \\
\hline 2 & $\$ 40$ & $(1,2)$ & $\cdot[1,1\}$ & $(2,1)$ & $-[1,1]$ & $(2,1)$ & $(1,2)$ \\
\hline 3 & 543 & $b(1,1)$ & $(1,2)$ & $(1,2)$ & $(1,2)$ & $\{1,2\}$ & $(1,1)$ \\
\hline 4 & S82 & $(1,1)$ & $\because(1,1)$ & $b(1,1)$ & $-[1,1\}$ & $b(1,1)$ & $\bullet[1,1)$ \\
\hline 8 & 607 & $\{2,1\}$ & $(2,1)$ & $\{1,1\}$ & $(2,1)$ & $b(1,1)$ & $(2,1)$ \\
\hline 6 & 768 & $*(1,1)$ & $+(1,1)$ & $(1,1)$ & $\bullet(1,1)$ & $-(1,1)$ & $\bullet(1,1\}$ \\
\hline 7 & 942 & $(2,1)$ & $(1,2)$ & $(1,2)$ & $(1,2)$ & $(1,2)$ & $(2,1)$ \\
\hline 8 & 991 & $(2,1)$ & $(2,1)$ & $-(1,1)$ & $(2,1)$ & $b(1,1\}$ & $(2,1\}$ \\
\hline 9 & 1041 & $(1,2)$ & $(1,2)$ & $(2,2)$ & $(1,2)$ & $(2,1)$ & $(1,2)$ \\
\hline 10 & 1101 & $(1,2)$ & $(1,2)$ & {$[2,1)$} & $(1,2)$ & $(2,1)$ & $(1,2)$ \\
\hline
\end{tabular}

Convex outward.

boncave outward.

coblique nodsl line.

Generally, the product of an exciting force and the corresponding displarement gives the work done by the force. Since the work done represents the energy input into the vibrating structure, it must have a strong correlation with the vibration energy defined in this research. This correlation is demonstrated approximately for the aforementioned frequencies of the gearbox in the following manner.

The mode shape obtained by the eigenvalue analysis is not the actual displacement, but the relative displacement at every node. However, all the eigenvectors calculated in this research are normalized with respect to the mass matrix. Therefore, if every eigenvector component is listed at a certain node, it might represent the relative linear and rotational components of the displacement at the node. The components at the position of the bearings are selected from the results of the calculation and normalized with respect to the maximum value to obtain the displacements. Figure 3 illustrates the displacements at bearing $\mathrm{I}$. The abscissa indicates the mode order from 1st to 30th. For example (Figs. 3(a) and (c)), the maximum displacements in the $\mathrm{X}$ and $\mathrm{Z}$ directions originate in the $27 \mathrm{th}$ and 28 th mode shape, respectively.

The product of the $\mathrm{X}$ and $\mathrm{Z}$ components of the applied unit load and the corresponding displacements at the bearing positions is defined here as the work done by the load,

$$
\mathrm{U}=\left|\mathrm{u}_{1}-\mathrm{u}_{2}\right| \sin \alpha_{\mathrm{w}}+\left|\mathrm{w}_{1}-\mathrm{w}_{2}\right| \cos \alpha_{\mathrm{w}}
$$

where $u$ and $w$ are the displacements in $X$ and $Z$ directions; $\alpha_{w}$ is the operating pressure angle; subscripts 1 and 2 indicate the position of bearings 1 and 2 , respectively. The displacernents $u_{1}$ and $w_{1}$ are taken from the results at the aforementioned 10 frequencies: the 2nd, 4 th, 5 th, 6 th, 7 th, 11 th, $12 \mathrm{th}, 13 \mathrm{th}, 15 \mathrm{th}$, and 17 th modes in Fig. 3. A similar method is used to obtain $u_{2}$ and $\mathrm{w}_{2}$, and the work done is calculated from Eq. (12). The work done is not the actual, but the relative work. Figure 4 shows the comparison of the work and the calculated vibration energy of the gearbox. The energy is approximately proportional to the work. This is as expected and suggests that the relative vibration magnitude can be estimated approximately from the work.

\section{OPTIMUM DESIGN OF GEARBOX}

\section{Design of the Top Plate}

The vibration energy of the gearbox caused by unit exciting force $1 \mathrm{~N}$ with initial thickness is shown by the broken line in Fig. 5 . The abscissa indicates the exciting frequency, and the peaks represent the resonance. In the first example, the top plate of the gearbox is designed through the energy minimization at $1260 \mathrm{~Hz}$. This frequency coincides with the gear mesh frequency for a 28 -tooth gear

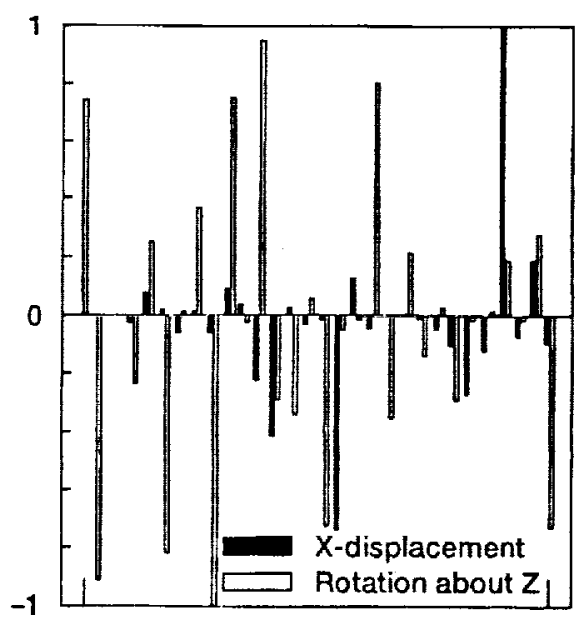

(a) Displacement along $X$ axis and rotation about $Z$ axis.

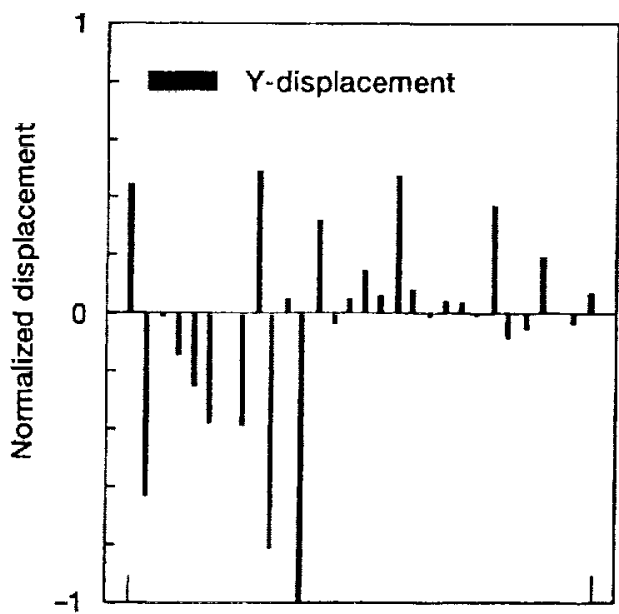

(b) Displacement along $Y$ axis.

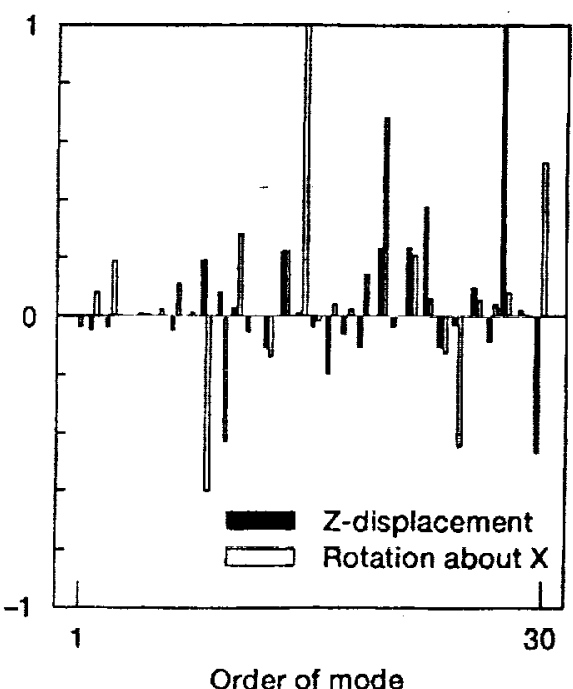

(c) Displacement along $Z$ axis and rotation about $X$ axis.

Figure 3.-Relative displacements at the positions of bearing 1 (nomalized by the maximum displacement). 


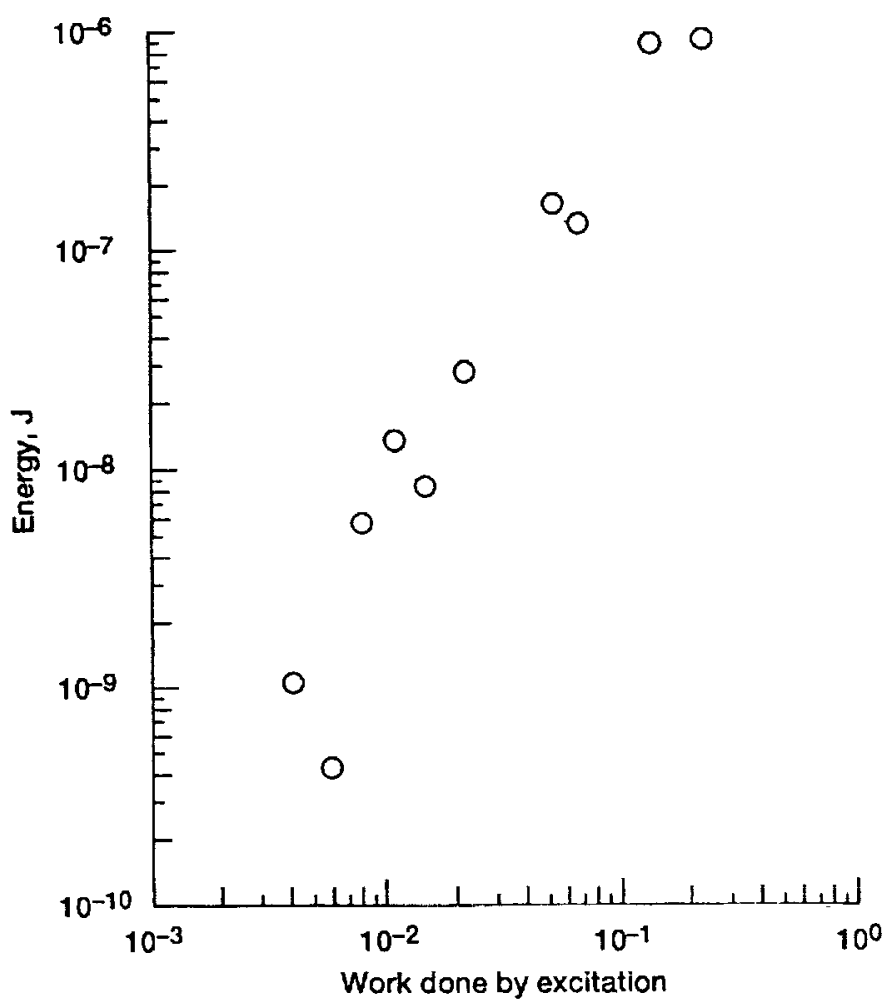

Figure 4.-Relation between vibration energy of gearbox and work done by exciting force. (Work done is calculated from the nomalized displacements.).

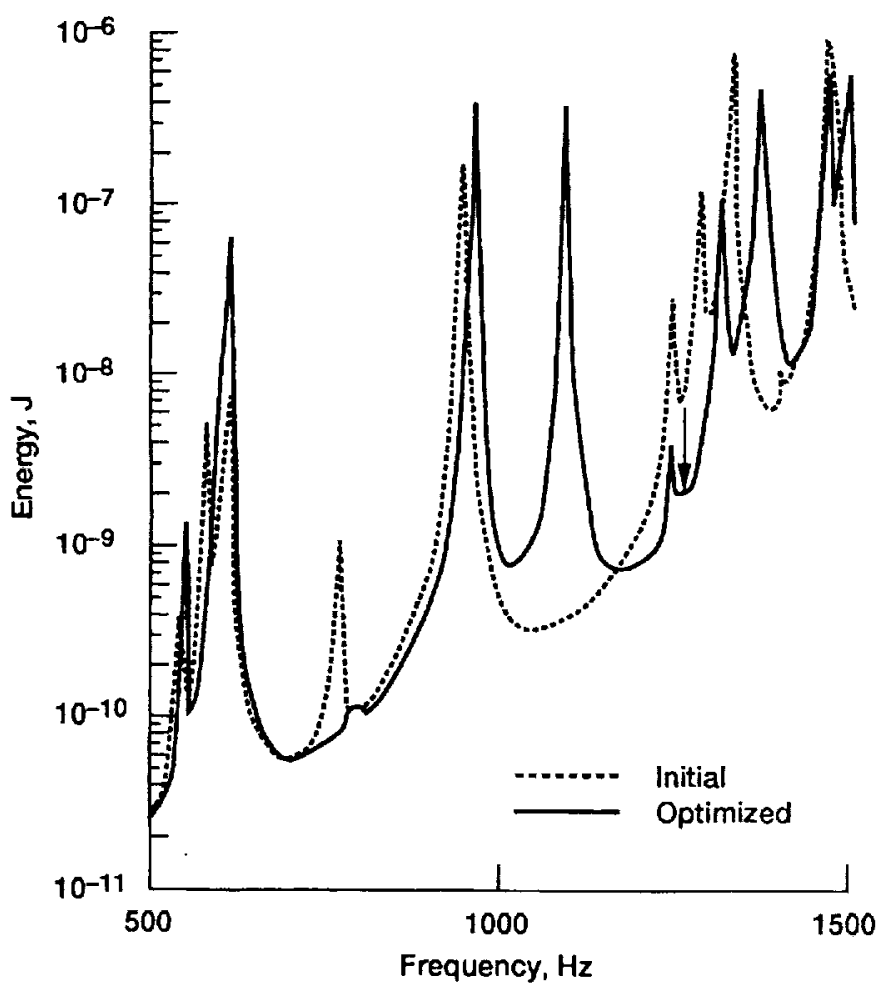

Figure 5.-Frequency response of gearbox due to unit exciting force. (Top plate is optimized.) operating at $2700 \mathrm{rpm}$. The initial vibration energy at this frequency is about $0.976 \times 10^{-8} \mathrm{~J}$. The limits of thickness are specified as $2 \mathrm{~mm} \leqq \mathrm{t} \leqq 12 \mathrm{~mm}$.

The energy converges to a value of about 19 percent of the initial value after six iterations (Fig. 6). The frequency response after optimization is shown by the solid line in Fig. 5. The resonance peak at $1280 \mathrm{~Hz}$ shifts to approximately $1320 \mathrm{~Hz}$. The response variation may look slight in the figure, but the vibration energy is reduced. This optimum design solution required about $875 \mathrm{sec}$ per iteration on the Cray XMP/28.

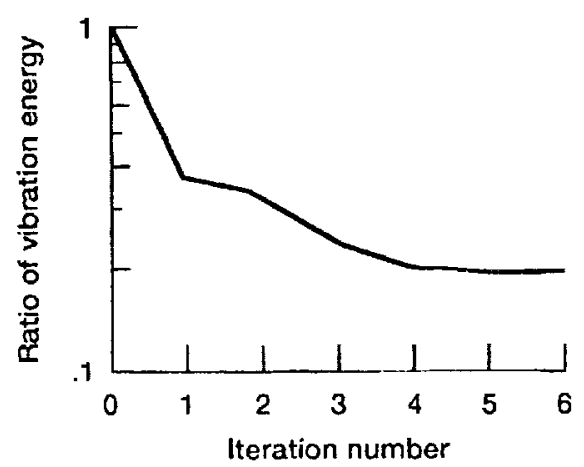

Figure 6.-Convergence of vibration energy. (Top plate is optimized.)

Figure 7 illustrates the optimum shape of the top plate. The thickness increases above bearing $I$ and near the edge that connects to surfaces 2 and 4 . The displacement along the $\mathrm{Y}$ axis at bearing 1 is large in the 12th mode, $1277 \mathrm{~Hz}$ (Fig. 3(b)). The increase in thickness causes an increase of rotational rigidity about the $\mathrm{X}$ axis to control the displacement. Figure 8 shows the energy share of each surface before and after the optimization. The energy reduction in the top plate is comparatively small. However, the variation in thickness of the top plate causes a vibration energy reduction in the other plates.

\section{Design of the Top Plate and Two Side Plates}

In the second example, two side plates 3 and 5 as well as the top plate are optimally designed. The side plates are selected because they do not support the shafts. The conditions of excitation and constraint are the same as in the first example. Figure 9 shows the frequency response. The energy is considerably reduced between 1180 to $1370 \mathrm{~Hz}$, and the vibration energy reduction is larger than in the first example. The energy is reduced sharply at the first iteration and converges on the value of approximately 3 percent of the initial value (Fig. 10).

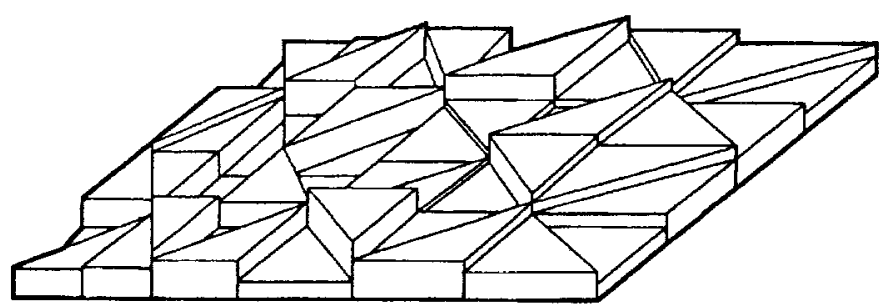

Figure 7.-Optimum shape of gearbox top plate. 


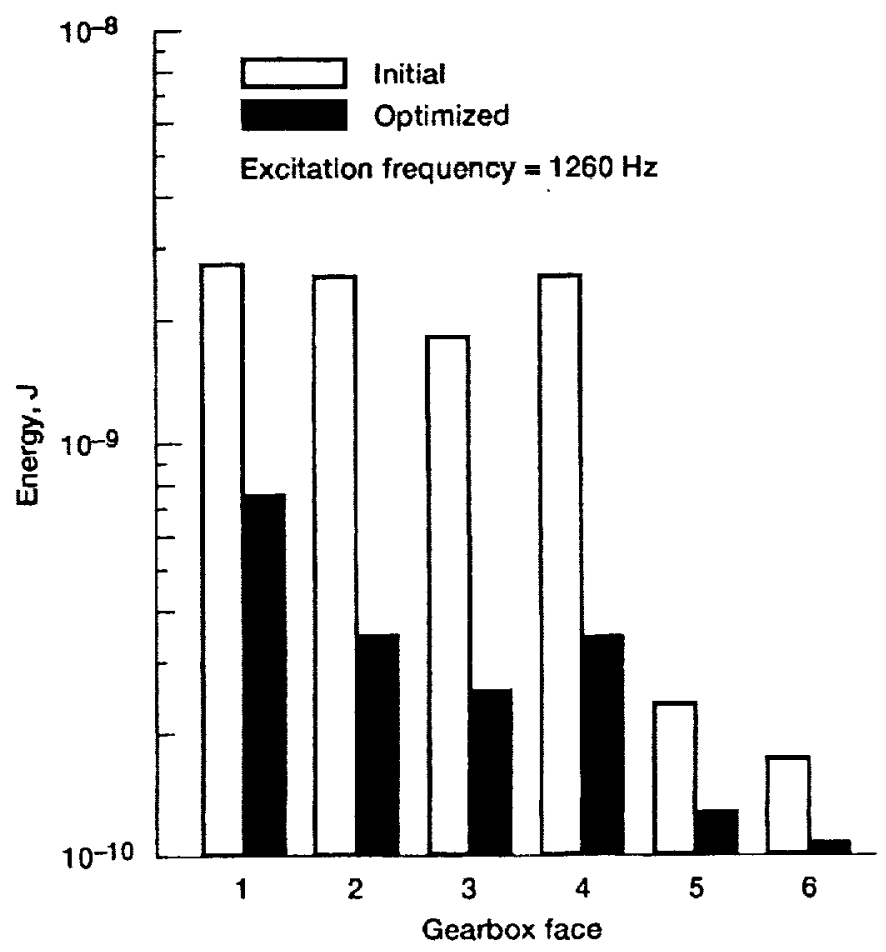

Figure 8.-Share of vibration energy. (Top plate is optimized.)

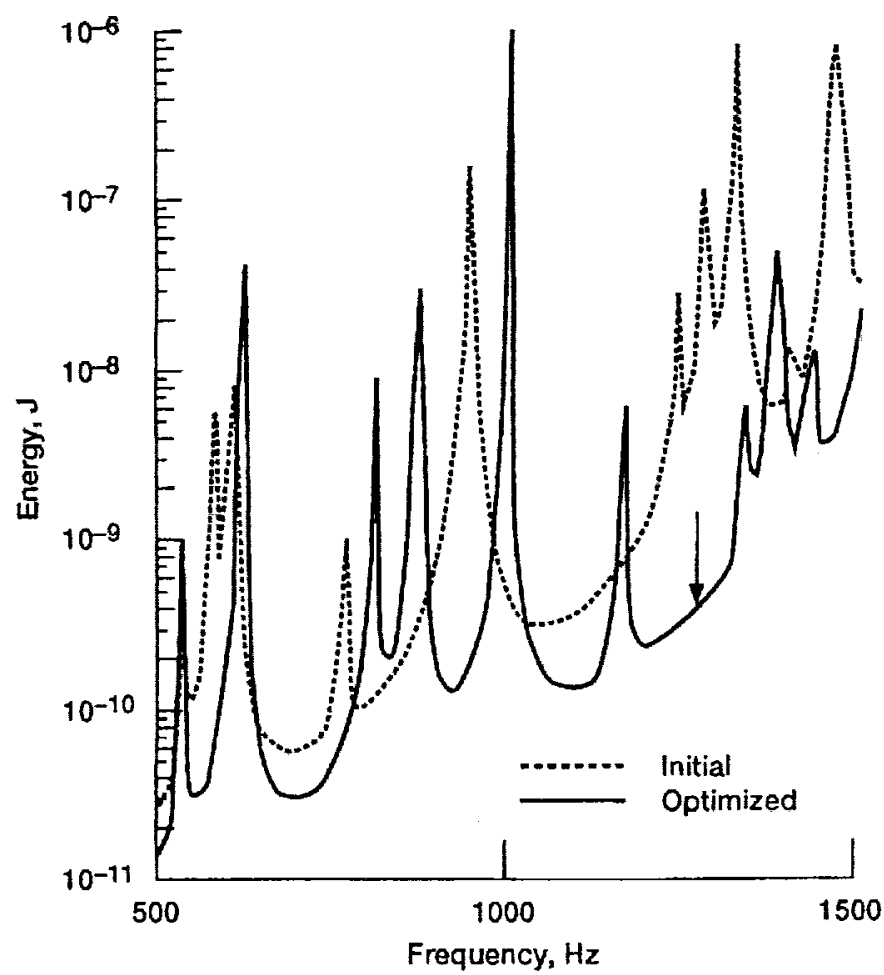

Figure 9.-Frequency response of gearbox due to unit exciting force. (Top plate and two sides are optimized.)

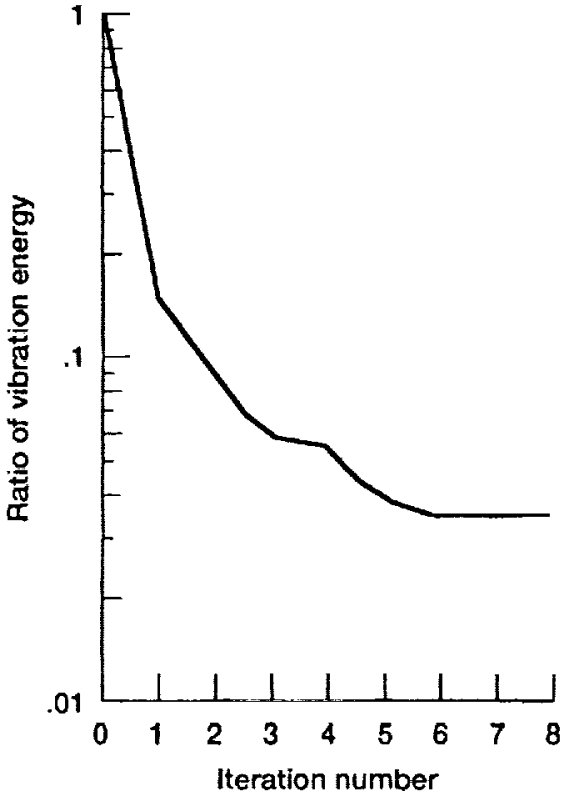

Figure 10.-Convergence of vibration energy. (Top plate and two sides are optimized.)
The optimum shape of the top plate and two side plates are illustrated in Fig. 11. The thickness distribution of the top plate is similar to the result in the first example. However, the weight of the top plate is reduced approximately 15 percent by the optimization as compared to the initial weight. The optimum shapes of the two side plates are similar to each other. The thickness increases at the bottom and sides of the plates. The weight of plate 5 is also reduced approximately 7 percent from the initial weight. However, the weight of plate 3 increases approximately 23 percent because of the constraint condition of constant weight. Figure 12 shows the energy share of each surface. The energy is reduced in every surface, and the reduction in plate 3 is substantial. This may be partly due to the increase in weight.

\section{Verification and Revision of the Proposed Method}

An experimental verification may be required for this kind of design problem for two main reasons: to verify the proposed method and to estimate the error of the result. Method verification can be done using computer simulation instead of experimentation. After obtaining the optimum shape of a beam, the authors showed that the displacement amplitude was reduced considerably following optimization by solving the forced vibration problem of the beam (Inoue, Townsend, and Coy, 1992). This validates the proposed method itself. Estimating the error of the result depends on the assumptions and simplifications of modeling discussed in the section on modeling and eigenvalue analysis. A comparison with the measured frequency is presented also in this section.

A revision of the method could be completed later and applied to the design of low vibration and lightweight gearboxes by eliminating the constraint of constant weight and introducing appropriate side constraints. 

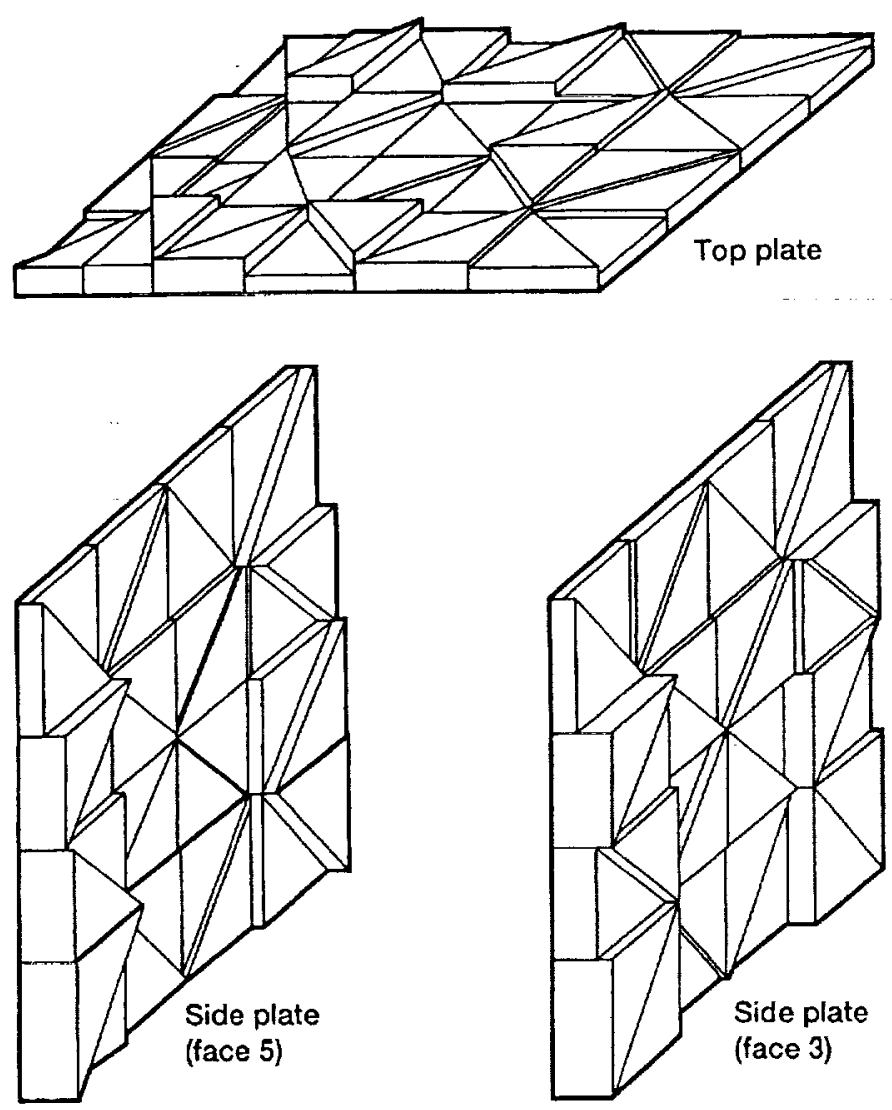

Figure 11.-Optimum shape of the top plate and two side plates of gearbox.

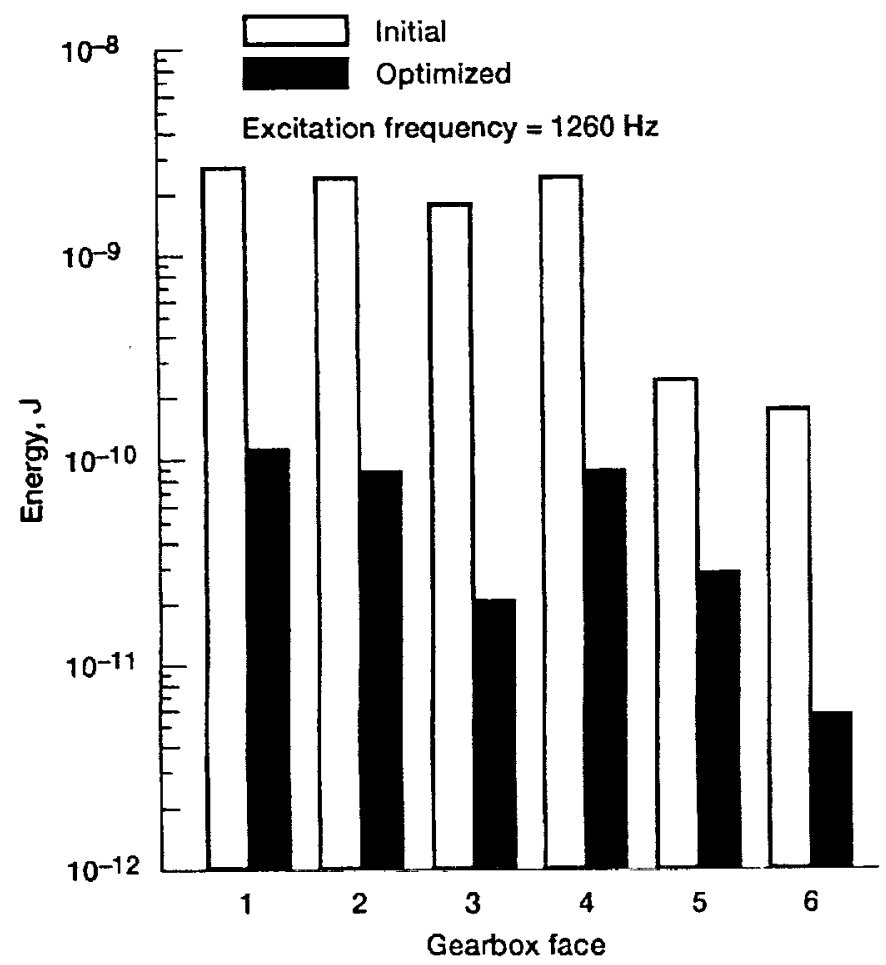

Figure 12.-Share of vibration energy. (Top plate and two side plates are optimized.)

\section{CONCLUSION}

The method proposed to design a low vibration gearbox is based on a finite element shell analysis, modal analysis, and a structural optimization technique. The overall vibration energy is adopted as the objective function and minimized by varying the element thickness under the constraint of constant weight. A computer program was developed for this purpose.

The computer program was applied to the design problem of a test stand gearbox used at NASA Lewis. The gearbox was excited by unit harmonic forces applied at the bearing positions in the direction of the line of action. The work done was estimated by the product of the bearing forces and the relative displacements obtained from the eigenvalue analysis. The work was approximately proportional to the total vibration energy of the gearbox. This suggests that the gearbox vibration magnitude can be estimated from the relative work.

The top plate and the two side plates of the gearbox were optimized. The vibration energy was reduced at the excitation frequency. The vibration reduction was abtained by variation of the thickness distribution and the consequent shift of weight from the top plate to the side plate. The contribution of each surface on the total vibration was determined. Optimization of the top plate only had considerable effect in reducing the vibration.

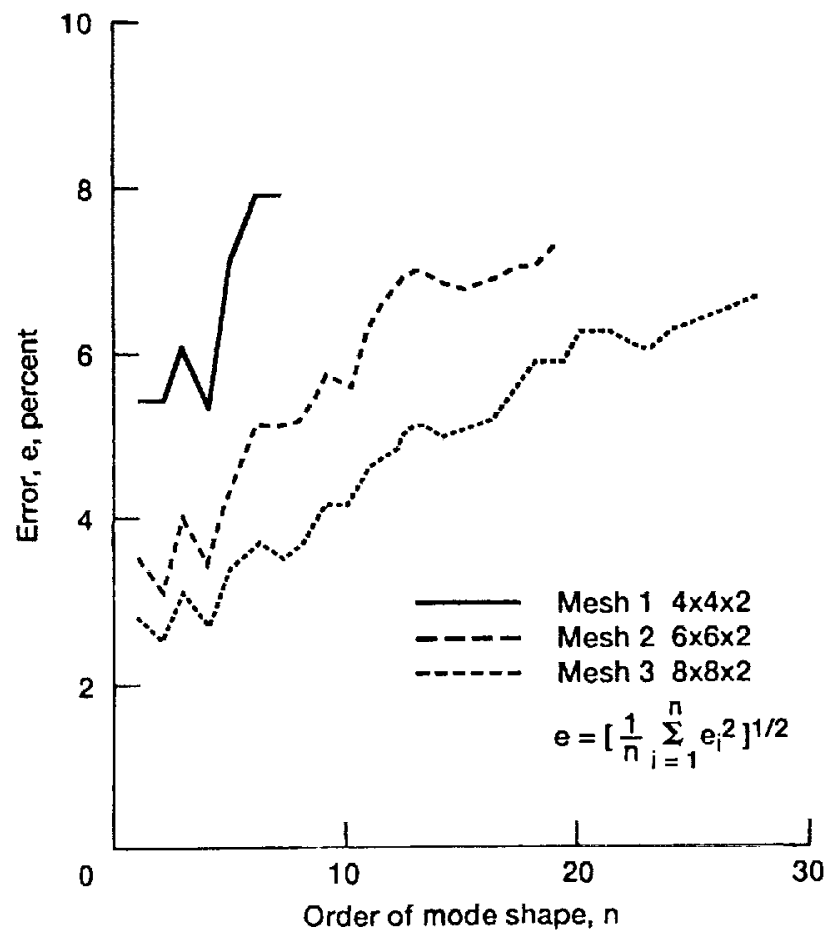

Figure 13.-Error of eigenvalue analysis of simply supported rectangular plate. 


\section{APPENDIX - ACCURACY OF THE FINITE ELEMENT ANALYSIS}

The eigenvalue problem of a simply supported rectangular plate is solved by the developed program. The plate is divided into $4 \times 4 \times 2,6 \times 6 \times 2$, and $8 \times 8 \times 2$ elements, respectively. The mesh patterns are similar to the pattern of the top surface of the gearbox shown in Fig. 2. Most of the computed natural frequencies are smaller than the analytical values, and the error depends on the mode shape or the mode order. The squared error arithmetic mean is evaluated and its square root is illustrated in Fig. 13. In the lower $\mathbf{3 0}$ gearbox modes, which are used for the modal analysis, each surface has 1 and 3 nodal lines at most. This mode corresponds to the 10th mode of the plate shown in Fig. 13, suggesting that the FE mesh in each surface of the gearbox may be used for the calculation of the mode shape with an error of approximately 10 percent. This does not directly show the error of the gearbox vibration because of its complexity.

\section{REFERENCES}

Choy, F.K., et al., 1991, "Modal Analysis of Multistage Gear Systems Coupled with Gearbox Vibrations," Proceedings of the International Conference on Motion and Power Transmissions, JSME, Hiroshima, Japan, pp. 110-116.

Fox, R.L. and Kapoor, M.P., 1968, "Rates of Change of Eigenvalues and Eigenvectors," AIAA Journal, Vol. 6, No. 12, pp. 2426-2429.
Inoue, K., Kato, M., and Ohnuku, K., 1990, "Optimum Design of a Plate on the Minimization of the Vibration Energy," JSME Transactions, Vol. 56, No. 529, pp. 2361-2366.

Inoue, K., Townsend, D.P., and Coy, J.J., 1992, "Minimization of the Vibration Energy of Thin-Plate Structures," to be presented at the ASME Design Automation Conference, Phoenix, Sept. 13-16, 1992.

Kubo, A., Kiyono, S., and Fujino, M., 1986, "On Analysis and Prediction of Machine Vibration Caused by Gear Meshing. I: Nature of Gear Vibration and the Total Vibration - Excitation," JSME, Bulletin, Vol. 29, No. 258, pp. 4424-4429.

Lim, T.C., Singh, R., and Zakrajsek, J.J., 1989, "Modal Analysis of Gear Housings and Mounts," Proceedings of the 7th International Modal Analysis Conference, Society for Experimental Mechanics, Inc., Bethel, CT, Vol. II, pp. 1072-1078.

Oswald, F.B., et al., 1991, "Comparison of Analysis and Experiment for Dynamics of Low-Contact-Ratio Spur Gears," NASA: TM-103232.

Rosen, J.B., 1961, "The Gradient Projection Method for Nonlinear Programming. Part II: Nonlinear Constraints," SIAM Journal on Applied Mathematics, Vol. 9, No. 4, pp. 514-532.

Seybert, A.F. and Wu, T.W., 1989, BEMAP User's Manual, Ver. 2.4, Spectronics Inc.

Takatsu, N., et al., 1991, "Analysis of Experiment on the Vibration Transmission in a Single Stage Gearbox," Proceedings of the International Conference on Motion and Power Transmissions, JSME, Hiroshima, Japan, pp. 104-109.

Zienkiewicz, O.C. and Cheung, Y.K., 1967, The Finite Element Mechod in Structural and Continuum Mechanics, McGraw-Hill, New York. 


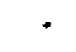


Public reporting burden for this collection of information is estimated to average 1 hour per response, including the time for reviewing instructions. searching existing data sources, gathering and maintaining the data needed, and completing and reviewing the collection of information. Send comments regarding this burden estimate or any other aspect of this collection of information, including suggestions for reducing this burden, to Washington Headquarters Services, Directorate for information Operations and Reports, 1215 Jefferson
Davis Highway. Suite 1204, Arlington, VA 22202-4302, and to the Office of Maragement and Budget, Paperwork Reduction Project (0704-0188), Washington, DC 20503.

\begin{tabular}{|l|c|c|}
\hline 1. AGENCY USE ONLY (Leave blank) & $\begin{array}{r}\text { 2. REPORT DATE } \\
1992\end{array}$ & $\begin{array}{r}\text { 3. REPORT TYPE AND DATES COVERED } \\
\text { Technical Memorandum }\end{array}$ \\
\hline
\end{tabular}

4. TITLE AND SUBTITLE 5. FUNDING NUMBERS

Optimum Design of a Gearbox for Low Vibration

6. AUTHOR(S)

Katsumi Inoue, Dennis P. Townsend, and John J. Coy

WU-505-63-36

1L162211A47A

7. PERFORMING ORGANIZATION NAME(S) AND ADDRESS(ES)

NASA Lewis Research Center

Cleveland, Ohio 44135-319I

and

Propulsion Directorate

U.S. Army Aviation Systems Command

Cleveland, Ohio 44135-3191

9. SPONSORING/MONITORING AGENCY NAMES(S) AND ADDRESS(ES)

National Acronautics and Space Administration

Washington, D.C. 20546-0001

and

U.S. Army Aviation Systems Command

St. Lou is, Mo. 63120-1798
8. PERFORMING ORGANIZATION REPORT NUMBER

$E-6622$

10. SPONSORING/MONITORING AGENCY REPORT NUMBER

NASA TM-105653

AVSCOM TR-91-C-027

\section{SUPPLEMENTARY NOTES}

Prepared for the Sixth International Power Transmission and Gearing Conference, sponsored by the American Society of Mechanical Enginecrs, Scottsdale, Arizona, September 13-16, 1992. Katsumi Inoue, National Rescarch Council, NASA Research Associate at Lewis Research Center (presently with Tohoku University, Sendai, Japan), Dennis P. Townsend and John J. Coy, NASA Lewis Researeh Center. Responsible person, Dennis P. Townsend, (216) 433-3955.

12a. DISTRIBUTION/AVAILABILITY STATEMENT

Unclassified - Unlimited

Subject Category 37

\section{ABSTRACT (Maximum 200 words)}

A computcr program was developed for designing a low vibration gearbox. The code is based on a finite element shell analysis, a modal analysis, and a structural optimization method. In the finite element analysis, a triangular shell element with 18 degrees-of-freedom is used. In the optimization method, the overall vibration energy of the gearbox is used as the objective function and is minimized at the exciting frequency by varying the finite element thickness. Modal analysis is used to derive the sensitivity of the vibration energy with respect to the design variable. The sensitivity is representative of both eigenvalues and eigenvectors. The optimum value is computed by the gradient projection method and a unidimensional search procedure under the constraint condition of constant weight. The computer code is applied to a design problem derived from an cxperimental gearbox in use at the NASA Lewis Research Center. The top plate and two side plates of the gearbox are redesigned and the contribution of each surface to the total vibration is determined. Results show that optimization of the top plate alone is effective in reducing total gearbox vibration.

\begin{tabular}{|c|c|}
\hline \multicolumn{2}{|l|}{$\begin{array}{l}\text { 14. SUBJECT TERMS } \\
\text { Gearbox; Vibration; Optir }\end{array}$} \\
\hline $\begin{array}{l}\text { 17. SECURITY CLASSIFICATION } \\
\text { OF REPORT }\end{array}$ & $\begin{array}{l}\text { 18. SECURITY CLASSIFICATION } \\
\text { OF THIS PAGE }\end{array}$ \\
\hline Unclassitied & Unclassified \\
\hline
\end{tabular}

15. NUMBER OF PAGES

12

16. PRICE CODE

$\mathrm{A} 03$

20. LIMITATION OF ABSTRACT SECUATTY CLASSIFICATION Unclassified 